\title{
EFFECTS OF LONG-TERM TREATMENTS WITH CAPTOPRIL ON BLOOD PRESSURE AND RENIN ACTIVITY IN THE STROKE-PRONE SPONTANEOUSLY HYPERTENSIVE RATS
}

\author{
Takushi X. WATANABE, Koichiro KAWASHIMA, Ken SAITO* \\ and Hirofumi SOKABE \\ Departments of Pharmacology and *Pathology, Jichi Medical School, \\ Tochigi-ken 329-04, Japan
}

Accepted June 20, 1980

\begin{abstract}
Antihypertensive effects of captopril, an orally active converting enzyme inhibitor were examined in the young and adult stroke-prone SHR (SHRSP) rats. The treatment was initiated at 6-7 and 14-18 weeks of age, and was continued for 12 and 17 weeks, respectively. The dosage of captopril was changed stepwise 3-30 and $3-100 \mathrm{mg} / \mathrm{kg}$, orally per day in the young and adult rats, respectively. The effects of hydralazine were also determined for comparison. Captopril had a chronic antihypertensive effect when given in doses of $30 \mathrm{mg} / \mathrm{kg}$ in the young and $100 \mathrm{mg} / \mathrm{kg}$ in the adult rats. Captopril had no significant effect on heart rate throughout the experiments, while hydralazine increased the heart rate. Treatment with captopril decreased the incidence of vascular disease in the young and the severity in the adult rats, respectively. A decrease in incidence of cerebral stroke in the adult SHRSP was also apparent. More than a ten fold increase in plasma renin activity and about a two fold increase in kidney renin activity were observed in both the young and adult SHRSP at the end of the treatments. The results demonstrate the efficacy of long-term treatment with captopril in the management of hypertensive disease in SHRSP rats.
\end{abstract}

Captopril (D-3-mercapto-2-methylpropanoyl-L-proline, SQ 14,225) is a nonpeptidic and orally active inhibitor of converting enzyme $(1,2)$. Captopril acutely and chronically reduced blood pressure in 2 kidney, 1 clip renal hypertensive (CLIP) and spontaneously hypertensive (SHR) rats (3-5). The doses required for the chronic antihypertensive effect were 10-30 times higher than those required for the acute effect (3-5). In addition, the antihypertensive mechanism of captopril remained unclear $(4,5)$.

We have reported the acute effect of captopril on blood pressure (BP) and plasma renin activity (PRA) in stroke-prone SHR (SHRSP) rats $(6,7)$. Captopril $(3.0 \mathrm{mg} / \mathrm{kg}$, p.o.) lowered mean BP markedly and increased PRA significantly in conscious and unrestrained SHRSP rats $1 \mathrm{hr}$ after administration. Since control PRA in the SHRSP is markedly elevated $(7,8)$, the marked BP decrease after captopril treatment could be due, at least in part, to the suppression of angiotensin II formation. However, to explain the vasodepressor effect of captopril in the SHR which have normal PRA values, other mechanisms have to be considered (7).

The purpose of the present study was to examine the long-term effects of captopril on BP, and plasma and kidney renin activities (KRA) in SHRSP. In this strain, BP becomes extremely high, more than half the number of rats have a cerebral stroke, and PRA increases 
at extremely high levels after 20 weeks of age. Thus this strain is considered to be a good model of malignant hypertension in human. We used 5-6 or 13-17 weeks of age of SHRSP, and termed them "young" and "adult" rats, respectively. The young were considered to be at the pre-hypertensive stage while the adult had an established hypertension. Hydralazine, a widely used antihypertensive vasodilator drug, was selected as the reference drug, because the antihypertensive effect is well established in the rats $(5,9)$. Captopril has an unique mechanism of action, and other antihypertensive drugs with similar mechanisms of action are not available.

\section{MATERIALS AND METHODS}

Hypertensive rats: Male SHRSP rats of F45-46, 5-6 (young) or 13-17 (adult) weeks of age were used. SHRSP rats had been transferred from Professor K. Okamoto's laboratory at F36 generation. The animals were fed a rat chow containing $0.24 \%$ sodium (Oriental Yeast MF) and tap water ad libitum. The body weights of the young and adult rats were 65-70 $\mathrm{g}$ and 225-235 g, respectively.

Experimental design: Six experimental groups, 9-10 rats each were made up of different combinations of age and drugs. The drug treatments were started at 6-7 and 14-18 weeks of age and were continued for 12 and 17 weeks in young and adult SHRSP rats, respectively, after control observation for one week. The drugs were administered once a day by a gastric tube at 10:00-11:00 hours. Captopril (SQ) (Sankyo) and hydralazine hydrochloride (HZ) (Yamanouchi) were used. The drugs were dissolved with $\mathrm{H}_{2} \mathrm{O}$ in a volume of $5 \mathrm{ml} / \mathrm{kg}$ body weight. For the control rats, $\mathrm{H}_{2} \mathrm{O}$ in an amount of $5 \mathrm{ml} / \mathrm{kg}$ was given by the same mode. The doses of SQ were increased stepwise from 3 to $30 \mathrm{mg} / \mathrm{kg}$ every 2 weeks in the young and from 3 to $100 \mathrm{mg} / \mathrm{kg}$ every 3 weeks in the adults. The dose of $\mathrm{HZ}$ was fixed at $4 \mathrm{mg} / \mathrm{kg}$, and referred to the free base. Scheffe's $S$ and $\chi^{2}$ tests were used for statistical analyses.

Determination of blood pressure and heart rate: BP and heart rate (HR) were determined by a rat tail BP and HR determining system (Natume Seisakusho KN-0090) without anesthesia (9). The rat was warmed for about $1 \mathrm{~min}$ at $70^{\circ} \mathrm{C}$ before the determination. $\mathrm{BP}$ and HR were determined once a week during the experimental periods. The interval between the drug administration and determination was $5-8 \mathrm{hr}$, and randomized in each rat. At the end of the drug treatments, mean BP was determined directly without anesthesia or restraint through a cannula which had been inserted into the abdominal aorta the day before (8). Good correlations between indirect tail BP and direct mean BP at the end of the treatment were seen in the young and adult $(\mathrm{r}=0.865$ and $0.782, \mathrm{P}<0.005$, respectively).

Postmortem examination and determination of renin activities: After the direct $\mathrm{BP}$ measurement, $0.5 \mathrm{ml}$ of blood sample was obtained from the aortic cannula. The rats were then anesthetized with ether and exsanguinated. The kidneys were removed, immersed in cold water and the remaining blood was squeezed out. The rats were inspected marcroscopically and the cranial cavity was opened to observe the brain. The heart and kidney were weighed before fixation. Data from rats which survived half of the experimental period were included. Details of the histopathological examination were as reported previously (9). 
PRA and KRA were measured by methods reported by Kawashima et al. (8). Briefly, a plasma sample was incubated with the rat plasma renin substrate pool. The amount of angiotensin I (ANG I) generated was determined by a radioimmunoassay. PRA was expressed as ng of ANG I formation per $\mathrm{ml}$ of sample plasma per hr. Kidney extract was prepared by homogenization with water and acidified to $\mathrm{pH}$ 3.0. After adjusting the $\mathrm{pH}$ to 7.0, the extract was incubated with rat plasma renin substrate pool. The amount of ANG I generated was determined by a radioimmunoassay. KRA was expressed as the reaction constant $\left(10^{-2} \mathrm{~K}\right)(10)$.

\section{RESULTS}

Body weight and heart rate (Figs. 1-2): In both young and adult SHRSP rats, the body weight increased at about an equal rate in each experimental group. The control groups showed fairly constant HR values during the experiment in the young and adult rats. HR of SQ groups showed fairly equal values with the controls, except at the 9th and 11th weeks in the young and at the 12th and 14th weeks in the adult, during which HR tended to decrease (12th and 14th weeks in the adult were statistically significant; $P<0.05$, respectively). In the $\mathrm{HZ}$ group, $\mathrm{HR}$ was markedly increased for the first 8 weeks in the adult rats when BP decreased ( $P<0.005-0.05$, except the 7th week). HR did not differ significantly in the young after $\mathrm{HZ}$ treatment.

Blood pressure (Figs. 3-4): In young SHRSP rats, tail BP of $\mathrm{H}_{2} \mathrm{O}$ group continued to increase for 11 weeks from about 130 to $230 \mathrm{mmHg}$. Mean BP determined directly at the 12 th week was lower than that determined by the indirect tail method at the 11th week. Theoretically, the indirect BP is more nearly equal to systolic pressure than mean

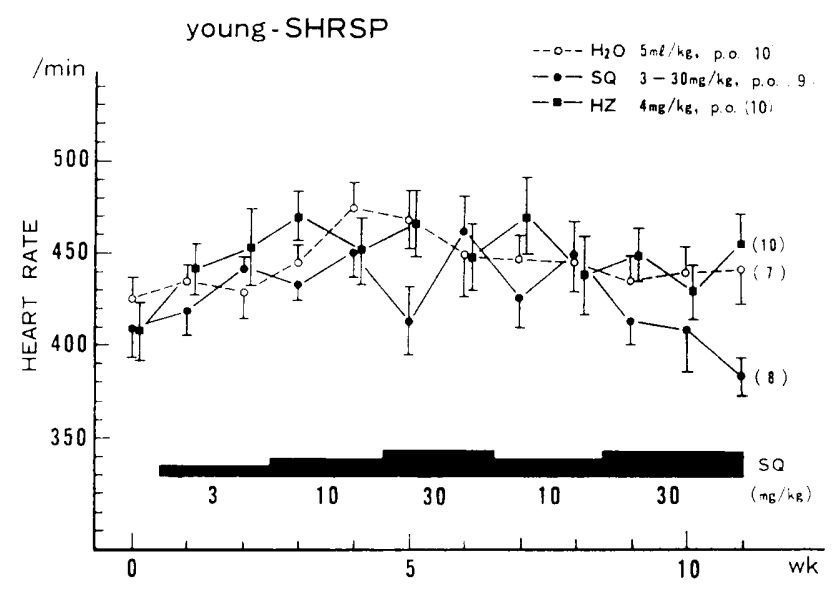

Fig. 1. Effects of captopril (SQ) and hydralazine (HZ) given orally for 11 weeks on heart rate in young-SHRSP rats. The control group given the distilled water is indicated as $\mathrm{H}_{2} \mathrm{O}$. Dose of captopril was increased or decreased stepwise as shown in a staircase belt. Vertical bars are SE of the mean. No. of rats at the start of the administration is in parentheses following explanation symbols. Final No. of rats at the end of the experiments is in parentheses, at the 12th week. 


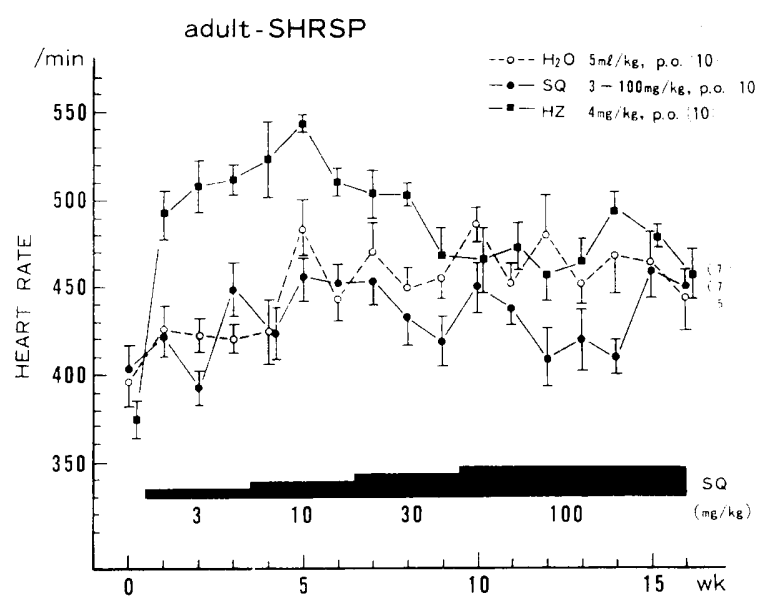

FIG. 2. Effects of captopril and hydralazine given orally for 16 weeks on heart rate in adult-SHRSP rats. Details are the same as in Fig. 1.

pressure and probably is the major reason for the higher values. In the SQ group, no significant difference from the control was observed for the first two weeks when a dose of $3 \mathrm{mg} / \mathrm{kg}$ was given. The difference was greater after the $3 \mathrm{rd}$ week when doses of over $10 \mathrm{mg} /$ $\mathrm{kg}$ were given. The dose of SQ was adjusted from the 5 th to the 9 th week so that decrease in the BP was almost equal that seen in the HZ group. The differences in the BP as compared to the $\mathrm{H}_{2} \mathrm{O}$ group after the $3 \mathrm{rd}$ week were statistically significant $(\mathrm{P}<0.005$, respectively). In the $\mathrm{HZ}$ group, $\mathrm{BP}$ differences from the $\mathrm{H}_{2} \mathrm{O}$ group were statistically significant $(\mathbf{P}<0.005$, respectively) throughout the experimental period except during the 2 nd week. The discrepancy between tail and mean BP in the drug treated groups, was larger than that seen in the $\mathrm{H}_{2} \mathrm{O}$ group.

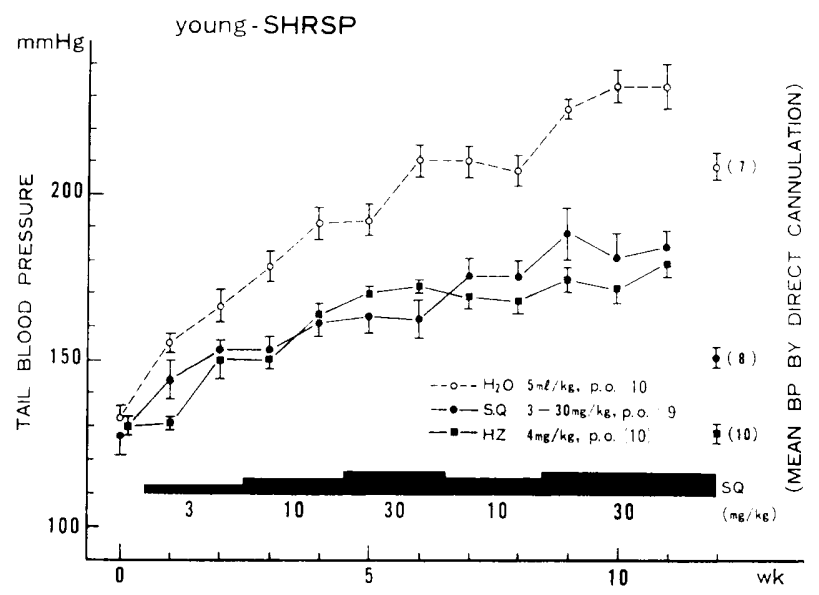

FIG. 3. Effects of captopril and hydralazine given orally for 12 weeks on blood pressure in young-SHRSP rats. Mean blood pressure was measured directly through a cannula inserted into the abdominal aorta. Details are the same as in Fig. 1. 


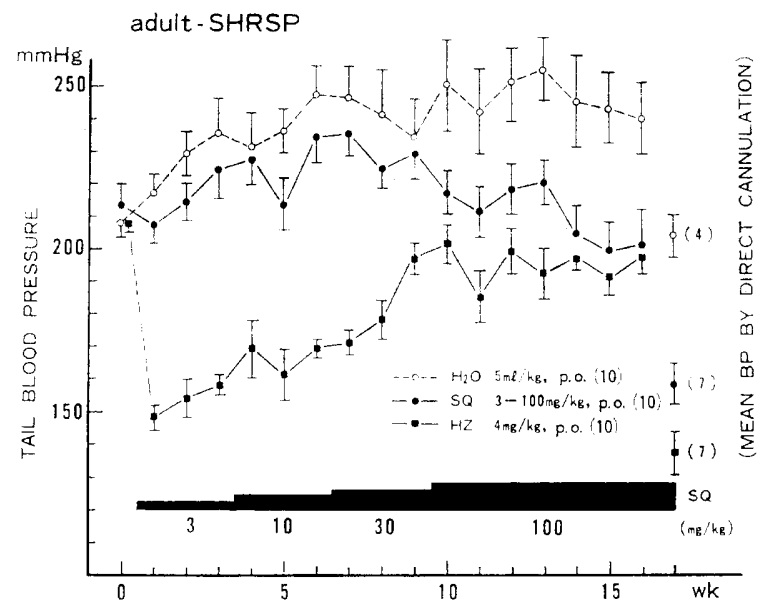

FIg. 4. Effects of captopril and hydralazine given orally for 17 weeks on blood pressure in adult-SHRSP rats. Mean blood pressure was measured directly through a cannula inserted into the abdominal aorta. Details are the same as in Fig. 1.

In the adult SHRSP rats, tail BP increased for the first 6 weeks from 210 to $240 \mathrm{mmHg}$, and reached a plateau from the 7 th to the 16 th week in the $\mathrm{H}_{2} \mathrm{O}$ group. Mean BP determined at the 17 th week was lower than tail BP at the 16 th week. The difference was greater than that in the young rats. SQ in a dose of $100 \mathrm{mg} / \mathrm{kg}$ lowered BP after the 10 th week. BP decreased gradually from the 13th to the 16 th week. The $\mathrm{BP}$ differences from $\mathrm{H}_{2} \mathrm{O}$ group at the 10th and from the 13 th to the 17 th week were statistically significant $(\mathrm{P}<0.005-0.05)$. In the $\mathrm{HZ}$ treated group, marked BP decrease was seen from the 1st week of the treatment. The BP returened gradually to pretreatment level from the 2 nd to the 9 th week, then became fairly constant from the 10 th to the 16 th week. The BP differences from the $\mathrm{H}_{2} \mathrm{O}$ group throughout the experimental period were statistically significant $(P<0.005-0.025)$. The discrepancy between the mean and tail BP in drug treated groups was larger than that in $\mathrm{H}_{2} \mathrm{O}$ group, as seen in the young rats.

Postmortem examination (Table 1-2): In the young rats, a few foci of angionecrosis, or necrotizing angitis were seen mostly in the kidneys of control rats. In the drug treated groups, no vascular lesion was found except for one rat in the SQ group with cerebral stroke. The incidence of the stroke in the drug treated groups was significantly reduced $(\mathrm{P}<0.005)$.

In adult rats in the control group, necrotizing angitis was not restricted to the kidney, and vascular lesions of moderate to marked degree were revealed in over a half the number of rats. In the drug treated groups, necrotizing angitis was found only in one rat in the $\mathrm{HZ}$ group. All other rats had a focal intimal thickening and/or disorganization of the structure of the arterioles of the kidneys. These changes were thought to be a cicatrized state of necrotizing angitis. The treatment with SQ significantly decreased heart weight in both the young and adult rats. $\mathrm{HZ}$ also tended to decrease heart weight, but the differences were not statistically significant. In the young and adult groups treated with SQ, kidney weight tended to increase, although the differences were not statistically significant. 
Plasma and kidney renin activities (Table 3): PRA in the young and adult SQ groups was 12 and 16 -fold higher than those of the controls, respectively $(\mathrm{P}<0.005)$. In the $\mathrm{HZ}$ groups, PRA was 4.3 and 3.7-fold higher than the controls in the young and adult, respectively, but the differences were not significant. KRA in the SQ groups were 1.8 and 2.0fold higher than those of the controls in the young and adult SHRSP $(\mathrm{P}<0.005$ and $<0.05$, respectively). In the $\mathrm{HZ}$ group, KRA of the young were 1.5-fold higher than those of $\mathrm{H}_{2} \mathrm{O}$ group, but the difference was not statistically significant.

TABLE 1. Vascular disease and stroke in the SHRSP rats treated with captopril and hydralazine

\begin{tabular}{|c|c|c|c|c|c|c|c|c|c|}
\hline & \multirow{2}{*}{ Treatment } & \multicolumn{5}{|c|}{ Vascular disease } & \multicolumn{3}{|c|}{ Stroke ${ }^{b}$} \\
\hline & & $(-\infty)$ & $(+)$ & $(++)$ & $(++t)$ & Total & $(-)$ & $(+)$ & Total \\
\hline \multirow[t]{3}{*}{ young-SHRSP } & $\mathrm{H}_{2} \mathrm{O}$ & 0 & 8 & 0 & 0 & 8 & 8 & 0 & 8 \\
\hline & SQ & 8 & 0 & 1 & 0 & 9 & 7 & 1 & 8 \\
\hline & $\mathrm{HZ}$ & 10 & 0 & 0 & 0 & 10 & 10 & 0 & 10 \\
\hline \multirow[t]{3}{*}{ adult-SHRSP } & $\mathrm{H}_{2} \mathrm{O}$ & 0 & 3 & 1 & 3 & 7 & 4 & 2 & 6 \\
\hline & SQ & 0 & 8 & 1 & 0 & 9 & 8 & 0 & 8 \\
\hline & $\mathrm{HZ}$ & 0 & 7 & 1 & 0 & 8 & 8 & 0 & 8 \\
\hline
\end{tabular}

All figures indicate No. of rats. aSeverity of vascular disease is shown as $(-),(+)$, $(++)$ and $(+++)$, indicating negative, mild, moderate, and severe, respectively. Incidence of stroke is shown as $(-)$ or $(-)$.

TABLE 2. Heart and kidney weights in the SHRSP rats treated with captopril and hydralazine

\begin{tabular}{llcll}
\hline & Treatment & $\begin{array}{c}\text { No. of } \\
\text { rats }\end{array}$ & $\begin{array}{c}\text { Heart weight } \\
(\mathrm{g} / 100 \mathrm{~g} \mathrm{BW})\end{array}$ & $\begin{array}{c}\text { Kidney weight } \\
(\mathrm{g} / 100 \mathrm{~g} \mathrm{BW})\end{array}$ \\
\hline young-SHRSP & $\mathrm{H}_{2} \mathrm{O}$ & 8 & $0.404 \pm 0.009$ & $0.728 \pm 0.017$ \\
& $\mathrm{SQ}$ & 8 & $0.347 \pm 0.003^{\circ}$ & $0.737 \pm 0.012$ \\
& $\mathrm{HZ}$ & 10 & $0.383 \pm 0.007$ & $0.725 \pm 0.014$ \\
adult-SHRSP & $\mathrm{H}_{2} \mathrm{O}$ & 7 & $0.446 \pm 0.027$ & $0.744 \pm 0.039$ \\
& $\mathrm{SQ}$ & 9 & $0.376 \pm 0.013^{\circ}$ & $0.787 \pm 0.022$ \\
& $\mathrm{HZ}$ & 8 & $0.425 \pm 0.012$ & $0.755 \pm 0.006$ \\
\hline
\end{tabular}

Values are mean \pm SEM. ${ }^{\text {a }} \mathrm{P}<0.005$ against $\mathrm{H}_{2} \mathrm{O} . \quad$ b $\mathrm{P}<0.05$ against $\mathrm{H}_{2} \mathrm{O}$.

TABLE 3. PRA and KRA of the SHRSP rats treated with captopril and hydralazine

\begin{tabular}{clccc}
\hline & Treatment & No. of rats & PRA $(\mathrm{ng} / \mathrm{ml}$ per hr $)$ & KRA $\left(10^{-2} \mathbf{K}\right)$ \\
\hline \multirow{2}{*}{ young-SHRSP } & $\mathrm{H}_{2} \mathrm{O}$ & 7 & $11.2 \pm 1.0$ & $72.0 \pm 9.8$ \\
& $\mathrm{SQ}$ & 8 & $134.1 \pm 25.9^{\mathrm{a}}$ & $131.3 \pm 10.7^{\mathrm{a}}$ \\
& $\mathrm{HZ}$ & 10 & $46.7 \pm 9.9$ & $107.9 \pm 10.9$ \\
\multirow{3}{*}{ adult-SHRSP } & $\mathrm{H}_{2} \mathrm{O}$ & 4 & $13.9 \pm 6.7$ & $53.7 \pm 6.9$ \\
& $\mathrm{SQ}$ & 7 & $227.2 \pm 24.8^{\mathrm{a}}$ & $101.4 \pm 13.0^{\mathrm{b}}$ \\
& $\mathrm{HZ}$ & 7 & $51.0 \pm 5.9$ & $63.7 \pm 9.3$ \\
\hline
\end{tabular}

Values are mean $\pm S E M$. a $P<0.005$ against $\mathrm{H}_{2} \mathrm{O}$. $\quad$ bP $<0.05$ against $\mathrm{H}_{2} \mathrm{O}$. 


\section{DISCUSSION}

SQ in doses of $10-30 \mathrm{mg} / \mathrm{kg}$, p.o. per day had chronic antihypertensive effects in young SHRSP rats when treatment was started at 5-6 weeks of age and was continued for 12 weeks. In the adult rats (13-17 weeks of age at the beginning of treatment) the antihypertensive effect was clearly seen only after the dose of SQ had been increased to $100 \mathrm{mg} / \mathrm{kg}$. HR did not change significantly with SQ treatment in either group of SHRSP rats. HZ increased HR while the BP decreased markedly in the adult rat, as reported previously (9), because of cardiac acceleration due to the decreased total peripheral resistance. We have no explanation for the unchanged HR after SQ treatment.

Although the discrepancies between BP values obtained directly and indirectly were large, the results and conclusions obtained by direct cannulation are in agreement with those obtained by indirect measurements. In our experiences, tail BP was much the same as mean BP directly obtained in deoxycorticosterone and salt or two kidney, one clip renal hypertensive rats (9). Theoretically, the direct BP is the mean and the indirect $\mathrm{BP}$ is closer to the systolic value. Therefore, the indirect $\mathrm{BP}$ would be greater than that obtained with direct measurements. In the present experiment, the differences were even greater than those theoretically expected, and are probably due to the extreme sensitivity of SHRSP rats to prewarming or handling during the indirect BP determination. The same phenomenon was also observed in work on SHRSP and SHR rats $(8,11)$.

Antonaccio et al. (5) reported that SQ given to SHR rats chronically caused a progressive cumulative reduction of BP. In the present experiment, the cumulative effect of SQ was not clearly seen in SHRSP rats. $\mathrm{HZ}(4 \mathrm{mg} / \mathrm{kg}, \mathrm{p} . \mathrm{o}$.) showed tolerance to the antihypertensive effects in the adult rats, as reported before in the 2 kidney, 1 clip rats (4).

In the present studies $30-100 \mathrm{mg} / \mathrm{kg}$, p.o. per day of SQ was required to produce an antihypertensive effect in SHRSP rats. These doses are in accord with those previously reported $(4,5)$. To lower BP acutely, $3 \mathrm{mg} / \mathrm{kg}$ p.o. is sufficient for $\operatorname{SHR}$ or $\operatorname{SHRSP}(2,3$, 6). Our results demonstrate a so-called tolerance. However, the exact nature may be clarified only after daily monitoring of BP, continuously for $24 \mathrm{hr}$.

The treatment with $\mathrm{SQ}$ and $\mathrm{HZ}$ decreased the incidence of the vascular lesions in the young rats. In adult rats in the control group, the vascular lesions are more advanced. In the drug treated groups, the vascular lesions were found in cicatrized state, except for one rat. Since vascular lesions had already developed in the adult SHRSP of 13-17 weeks of age, it is clear that the artihypertensive treatments prevented further aggravation of the vascular lesions. The treatment with either drug also tended to decrease the incidence of stroke in the adult rats.

In our previous report, the PRA values at the age of 10,20 and 30 weeks of SHRSP rats were about 10,35 and $45(\mathrm{ng} / \mathrm{ml}$ per $\mathrm{hr})$, respectively (8). In the present study, PRA values of $\mathrm{H}_{2} \mathrm{O}$ groups in the young and adult were smaller than our reported data at the same ages. This discrepancy may be explained by the fact that the rats with high PRA values died before the end of this experiment. KRA value of $\mathrm{H}_{2} \mathrm{O}$ group in the young rats was higher than that in the adult, and these results are in accord with previous data which 
indicated that KRA decreased with age in SHRSP rats (8). We have reported that acute SQ treatments increased PRA in SHRSP. This was also true in the long-term treatment study, and SQ treatment increased also KRA. The increase in PRA and KRA may be explained by the decreased feedback inhibition of ANG II on renin release from the kidney, by the decreased renal perfusion pressure, and by the compensatory increase of the renal sympathetic nervous activity. The elevation of PRA and KRA after SQ treatments was much higher than $\mathrm{HZ}$ treatments in the SHRSP.

We have reported that the acute vasodepressor effect of SQ in SHRSP rats at about 20 weeks of age was at least partly due to the suppression of ANG II formation, because PRA was elevated in SHRSP of this age (6-8). However, BP was moderately decreased with SQ in the main strain of spontaneously hypertensive rats, of which PRA value was within a normal range. BP in normotensive strains of Donryu or Wistar-Kyoto rats was only slightly affected with SQ. The results cannot be explained only by suppression of the renin-angiotensin system $(6,7)$. In the present studies of long-term treatments with $S Q$, its antihypertensive effect cannot be interpreted as being due to inhibition of the converting enzyme as SQ was more effective in the young than in the adult SHRSP. Both young and adult groups revealed similar PRA values, although PRA increased after 20 weeks of age, in our previous studies $(7,8)$.

The mechanisms of antihypertensive effect of SQ have not been clarified. However, several possibilities have been considered including inhibition of converting enzyme, increased kinin formation (12), increased natriuresis (13), activation of renal prostaglandins (14), arteriolar and venular vasodilatation (15), and decreased sensitivity to norepinephrine (16). From the present studies we can only say that the antihypertensive effect of SQ is not entirely due to inhibition of converting enzyme, but some other mechanisms must also be considered.

Acknowledgements: We thank Miss Y. Kurihara, Mrs M. Sokabe, and Miss S. Kurihashi for technical assistance.

\section{REFERENCES}

1) Ondetti, M.A., Rubin, B. And Cushman, D.W.: Design of specific inhibitors of angiotensinconverting enzyme: A new class of orally active antihypertensive agents. Science $\mathbf{1 9 6}$. 441-444 (1977)

2) Rubin, B., Laffan, R.J., Kotler, D.G., O'Kreff, E.H., Demaio, D.A. and Goldberg, M.E.: SQ 14,225 (D-3-mercapto-2-methylpropanoyl-1.-proline), a novel orally active inhibitor of angiotensin I-converting enzyme. J. Pharmacol. exp. Ther. 204, 271-280 (1978)

3) Laffan, R.J., Goldberg, M.E., High, J.P., Schaffer, T.R., Waugh, M.H. and Rubin, B.: Antihypertensive activity in rats of SQ 14,225, an orally active inhibitor of angiotensin I-converting enzyme. J. Pharmacol. exp. Ther. 204, 281-288 (1978)

4) Antonaccio, M.J., Rubin, B., Horovitz, Z.P., Mackaniss, G. and Panasevich, R.: Longterm efficacy of captopri] (SQ 14,225) in 2-kidney renal hypertensive rats. Clin. Exp. Hyp. 1, 505-519 (1979)

5) Antonaccio, M.J., Rubin, B., Horovitz, Z.P., Lafian, R.J., Goldberg, M.E., High, J.P., HARRIS, DON N. AND ZAIDI, 1.: Effect of chronic treatment with captopril (SQ 14,225), an orally active inhibitor of angiotensin I-converting enzyme, in spontaneously hypertensive rats. Japan. J. Pharmacol. 29, 285-294 (1979)

6) Watanabe, T.X. AND SokABE, H.: Acute vasodepressor effect of D-3-mercapto-2-methyl- 
propanoyl-L-proline (SQ 14,225) in the stroke-prone substrain of spontaneously hypertensive rats (SHRSP). Japan. J. Pharmacol. 29, 133-135 (1979)

7) Sokabe, H., Kawashima, K. and Watanabe, T.X.: Acute effect of captopril on blood pressure and plasma renin activity in spontaneously hypertensive rats. Prophylactic Approach to Hypertensive Diseases, Edited by Yamori, Y., Lovenberg, W. And Freis, E.D., p. 347-351, Raven Press, New York (1979)

8) Kawashima, K., Shiono, K. And Sokabe, H.: Variation of plasma and kidney renin activities among substrains of spontaneously hypertensive rats. Clin. Exp. Hyp. 2, 229-245 (1980)

9) Watanabe, T.X., Shiono, K., Saito, K. and Sokabe, H.: Antihypertensive and antidiuretic effects of 3-hydrazino-6-[N,N-bis(2-hydroxyethyl)amino]-pyridazine (L 6150) in rats. Japan. J. Pharmacol. 28, 413-422 (1978)

10) Shiono, K. ANd SoKabE, H.: Renin-angiotensin system in spontaneously hypertensive rats. Am. J. Physiol. 231, 1295-1299 (1976)

11) Chiueh, C.C. AND Kopin, I.J.: Hyperresponsivity of spontaneously hypertensive rat to indirect measurement of blood pressure. Am. J. Physiol 234, H690-H695 (1978)

12) Muirhead, E.E., Prewitt, R.L. JR., Brooks, B. and Brosius, W.L. JR.: Antihypertensive action of the orally active converting enzyme inhibitor (SQ 14,225) in spontaneously hypertensive rats. Circulation Res. 43 Supp. I, I-53-I-59 (1978)

13) Bengis, R.G., Colfman, T.G., Yound, D.B. and McCaA, R.E.: Long-term blockade of angiotensin formation in various normotensive and hypertensive rat models using converting enzyme inhibitor (SQ 14,225). Circulation Res. 43 Supp. I, I-45-I-53 (1978)

14) Murthy, V.S., Waldron, T.L. AND Goldberg, M.E.: The mechanism of bradykinin potentiation after inhibition of angiotensin-converting enzyme by SQ 14,225 in conscious rabbits. Circulation Res. 43 Supp. I, I-40-I-45 (1978)

15) Cody, R.J. JR., Tarazi, R.C., Bravo, E.L. and Fouad, F.M.: Haemodynamics of orallyactive converting enzyme inhibitor (SQ 14,225) in hypertensive patients. Clin. Sci. Mol. Med. 55, 453-459 (1978)

16) Okuno, T., Kondo, K., Konishi, K., Saruta, T. and Kato, E.: SQ 14,225 attenuates the vascular response to norepinephrine in the rat mesenteric arteries. Life Sci. Oxford 25, 1343-1350 (1979) 